\title{
Common Practices Regarding Health and Status of Treatment Facilities in the Rural Areas of Sherpur Upazilla, Bogura, Bangladesh
}

\author{
Md. Abdul Alim*, Sarawat Rashid, Shaikh Shahriar Mohammad, Mohammad Munsur Rahman, \\ Jayanto Kumar Roy
}

Rural Development Academy (RDA), Bogura-5842, Bangladesh

Copyright $\bigcirc 2019$ by authors, all rights reserved. Authors agree that this article remains permanently open access under the terms of the Creative Commons Attribution License 4.0 International License

\begin{abstract}
A community based exploratory study was conducted among the villagers (sample size, $n=75$ ) of Kanopur, Shippur and Boraidaha village of Sherpur Upazila of Bogura district, Bangladesh to explore the common practices regarding health and treatment facilities in rural areas. This study was carried out through questionnaire, participatory rural appraisal and focus group discussion. The result showed that the socio-economic condition of these areas was average in terms of others villagers of Bogura region. The current health and treatment facilities of these areas were moderate and study found that about $80 \%$ people were aware about personal hygiene. The study reveals acidity and fever were the most frequent diseases and most of the people were happy about the service of doctors and Government health Centre. The study revealed that the half of the population of these areas knew about expanded programme on immunization and exclusive breastfeeding during lactation period. This study also exposed that around half of the respondents has no knowledge about Oral Rehydration Solution, extra salt used in eating, antibiotic course and even in danger sign during pregnancy of mothers and pneumonia among villagers. Besides, in case of family matters and during diseases condition, decision was taken by household head or sometimes husband and wife both. This study concluded that overall health care delivery system was moderate and actions should be taken to improve the overall scenario of health system of these regions.
\end{abstract}

Keywords Health Status, Socio-economic Condition, Personal Hygiene, Diseases, Treatment Facilities, Danger Sign etc.

\section{Introduction}

Community based study can only reflect the true picture of disease prevalence in a given community and what are their treatment facilities. The prevalence of period specific sickness and economic condition predictably hold an inverse relationship in rural area. Episodes of illnesses are reported to be higher for poor people due to their living conditions and nutritional status. The high incidence of morbidity cuts their household budget both ways i.e. not only they have to spend large amount of resources on medical care but are also unable to earn during this period. One possible consequences of this could be pushing these families into a zone of permanent poverty [1]. Health seeking behavior refers to the sequence of remedial actions that individuals undertake to rectify perceived ill health [2]. However, a large number of Bangladeshis, particularly in the rural areas have little access to healthcare facilities. It may seem that access to healthcare services for the insolvents, poor and the destitute countries to remain a day dream in one hand and on the other hand private sector healthcare service delivery with most modern and advanced facilities has developed remarkably for the affluent section of the society [3]. People in rural areas generally have less access to healthcare than their urban counterparts. Fewer medical practitioners, mental health programs and healthcare facilities in these areas often mean less preventative care and longer response times in emergencies. The lack of healthcare workers has resulted in unconventional ways of delivering healthcare to rural dwellers, including medical consultations by phone or internet as well as mobile preventative care and treatment programs [4]. The overall situation of health care system is poor in developing countries like Bangladesh due to inadequate access to modern health services and poor utilization. One of the public health challenges in Bangladesh is, therefore, to identify vulnerable groups and to provide them with needed preventive and curative health services [5]. Health is now universally regarded as an important index of human development. Ill health is both the cause and effect of poverty, illiteracy and ignorance. Policies of human development not only raise the income 
of the people but also improve other components of their standard of living, such as life expectancy, health, literacy, knowledge and control over their destiny. Health is both a major pathway to human development and an end product of it. Better health is both an objective of and an instrument for development. Poverty denies access to health in terms of status and services and health is a crucial link between poverty and reproductive choice. Health sector is an important indicator of the level of economic development and it includes mainly morbidity and mortality [6]. Due to huge number of population, Bangladesh faces double burden of diseases: Non-Communicable diseases: Diabetes, Cardiovascular diseases, Hypertension, Stroke, Chronic respiratory diseases, Cancer and Communicable diseases: Tuberculosis, HIV, Tetanus, Malaria, Measles, Rubella, leprosy and so on. However, recent statistics shows that non-communicable disease burden has increased to $61 \%$ of the total disease burden due to epidemiological transition. According to National NCD Risk Factor Survey in 2010, $99 \%$ of the survey population revealed at least one NCD risk factor and $\sim 29 \%$ showed $>3$ risk factors .Social transition, rapid urbanization and unhealthy dietary habit are the major stimulating reasons behind high prevalence of non-communicable diseases in Bangladesh remarkably in under-privileged communities such as rural inhabitants, urban slum dweller [7]. The total expenditure on healthcare as a percentage of Bangladesh's GDP was 3.35\% in 2009 [8]. The number of hospital beds per 10,000 populations is 3 [9]. The General government expenditure on healthcare as a percentage of total government expenditure was $7.9 \%$ as of 2009 and the citizens pay most of their health care bills as the out-of-pocket expenditure as a percentage of private expenditure on health is $96.5 \%$ [8]. Doctor to population ratio $-1: 2,00$ Nurse to population ratio $1: 5,000$ [10]. That's why the authors want to elucidate the prevalence of diseases in rural areas and status of treatment facilities available by the rural people.

\section{Objectives of Study}

The research has been undertaken for fulfilling the following objectives:

I. To know the current health status and common practices regarding health of village people in these areas.

II. To elucidate the socio-economic background regarding diseases pattern in rural areas.

III. To explore the situation of health service in rural areas of Bangladesh.

\section{Methodology of Study}

\subsection{Area of Study}

The study was conducted at Kanopur, Shippur and
Boraidaha villages under Sherpur Upazilla, Bogura, Bangladesh. The study areas were randomly selected to know the current health situation and it seems to these area has better health service due to near of Rural Development Academy (RDA).

\subsection{Data Collection Methods}

The data were collected through direct interview method through questionnaire, Participatory Rural appraisal (PRA) and Focus Group Discussion (FGD). The subjects were selected by multistage random sampling and examined throughout the area by a house to house survey. Only the seventy five households of the village were interviewed by using multistage random sampling method.

\subsection{Statistical Analysis}

Data were analysis by different types of simple statistical software like MS Excel, Mean, and Median etc.

\section{Results and Discussion of the Study}

Health is the basic rights of human beings and the healthcare needs of individuals living in rural areas are different from those in urban areas, and rural areas often suffer from a lack of access to healthcare. These differences are the result of geographic, demographic, socioeconomic, workplace, and personal health factors. The present study was conducted among seventy five persons of Kanopur, Shippur and Boraidaha village of Sherpur Upazila of Bogura district to investigate the present health status and treatment facilities among villagers. Although a small study, we have found some valid data and information which will be helpful for further study. Due to time limitation, only seventy five (75) respondents were participated through standard questionnaire. The results of the present study are presented below:

\subsection{Socio-economic Information of Respondents}

About $23 \%$ participants passed SSC, whereas 59\% have below SSC and 10\% has no knowledge about education among respondents $(\mathrm{n}=75)$. Most of the villagers are involved with agriculture (76\%) whereas; others are involved with service (8\%), business (4\%) and rest of the migrant and day laborers. However, in case of land area about $33 \%$ people have more than 6 bigha land along with homestead and rest of the land below 5 bigha and not less than 1 bigha. Due to some migrant these villages has yearly income are more than others village of the Sherpur upazilla. Among 75 respondents 57 have yearly income around 2 to 4 lakh and 10 respondents has yearly income more than 6 lakh. 


\subsection{Basic Information Regarding Health}

Sanitation is important for public health system and it is closely related to clean drinking water and adequate treatment and disposal of human excreta and sewage [11]. Preventing human contact with feces is part of sanitation, as is hand washing with soap. Sanitation system aim to protect human health by providing a clean environment that will stop the transmission of disease, especially through the fecal-oral route [12]. The present study found that most of the respondents used sanitary latrine $(n=58)$ among 75 respondents and rest of the respondents used others types of latrine for disposal of human excreta. In case of drinking water peoples of these region used tube wall water as their drinking water. No one used any source of water for their drinking purpose but peoples of these region used others source of water for their household activities. Sanitation system of these areas was quite good and peoples of these three region used soap and liquid soap for their hand wash.

\subsection{Awareness among Villagers Regarding Extra Salt Use in Eating and Antibiotic Course Completion}

A high salt intake has been shown to increase not only blood pressure but also the risk of stroke, left ventricular hypertrophy, and proteinuria [13]. The present study shows $48 \%$ population used extra salt during eating. WHO, 2015 report on public health regarding antibiotic used in treatment showed that most of the village peoples of Bangladesh have little knowledge about course of antibiotic used which is similar to the current study.

\subsection{Knowledge of the Respondents Regarding Exclusive Breastfeeding and EPI}

World Health Organization [14] has found that knowledge regarding exclusive breastfeeding and Expanded Promotion on Immunization (EPI) has increased among urban and village peoples but in the present study indicated that half of the populations of this region have no idea about exclusive breastfeeding and EPI. The villagers claimed that there is no community clinic in these areas for promoting awareness about above issues.

\subsection{Knowledge about Danger Sign in Pregnancy}

The present study found $68 \%$ population have no idea about danger sign during pregnancy but the other areas of the country especially in urban area most of the population have knowledge about the danger sign during pregnancy [14]. It seems that these areas healthcare facilities are not good due to lack of community clinic and far from district general hospital.

\subsection{Knowledge about Danger Sign in Pneumonia}

Pneumonia affects approximately 450 million people globally (7\% of the population) and results in about 4 million deaths per year [15]. So it urgent to build awareness among peoples about danger sign in pneumonia but in present study areas about $92 \%$ respondents has no idea about danger sign during pneumonia and rest of the participants has an idea about this.

\subsection{Occurrence of Diseases among Villagers and Service Received from the Government Health Centre}

Villagers $(n=75)$ of these areas were suffering from different types of diseases which is presented in figure 1. Fever (26\%), low back pain (15\%), acidity (10\%), common cold (14\%) are the frequent diseases in these area whereas; skin diseases, diarrhea, asthma, piles, hypertension, diabetics, headache etc. are the minor problems in study areas. Currently, Non Communicable Diseases (NCDs) account for $59 \%$ of total deaths in Bangladesh $(17 \%$ cardiovascular and $11 \%$ chronic respiratory diseases, $10 \%$ cancers, $9 \%$ injuries, $3 \%$ diabetes and $10 \%$ other NCDs) [8].The present study was slightly similar to the health and morbidity status survey- $2012(52.5 \%$ fever, $13.5 \%$ ulcer , $12.4 \%$ hypertension, $8.3 \%$ dysentery, $7.8 \%$ diabetes, $14 \%$ arthritis and so on. However, in Bangladesh service delivery constraints are a significant challenge in the public health system. Rural residents often experience barriers to healthcare that limit their ability to obtain the care they need [16]. The present study found that thirty five (35) participants did not attend any Govt. health service Centre to treat diseases among 75 participants due to lack of knowledge about health care facilities and far from their villages and rest of the members taken medical service from Govt. institution. In addition, the villagers were not happy about the service from government healthcare system during treatment and they claimed that the behavior of stuff was not satisfied.

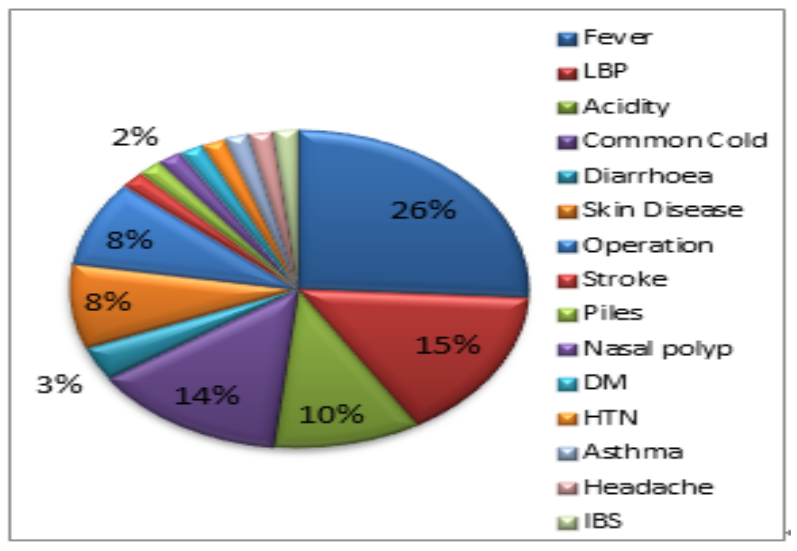

Figure 1. Occurrence of diseases among villagers

\subsection{Decision Taking in Family Matters and Treatment among Villagers}

Decision is an important fact when someone is suffering 
from any diseases and right decision can save life and mitigate the complications of the situation. Study found that in family matters and treatment decision taken by both (household head and wife) $56 \%$ and $48 \%$ respectively and only household head or husband has taken $40 \%$ decision in family matters and $44 \%$ decision in treatment in disease.

Table 1. Decision taking in family matters and treatment

\begin{tabular}{|l|l|l|}
\hline Decision taker & Family matters (\%) & Treatment (\%) \\
\hline HH head (Husband) & 40 & 44 \\
\hline Wife & 4 & 8 \\
\hline Both & 56 & 48 \\
\hline
\end{tabular}

\section{Conclusions}

The current health and others diseases condition was moderate at the selected three village due to their average socio-economic condition. Half of the population in these areas knew the basic health knowledge and around $80 \%$ people maintain the personal hygiene. Study found that there was a significant percentage of peoples did not aware about basic information about health like EPI, exclusive breastfeeding, extra salt used in eating, antibiotic course completion and even in case of danger sign during pregnancy and pneumonia. So, government or related organization should build awareness in these areas. Moreover, different types of diseases were frequent occurred in these areas among villagers and they received treatment from medi-shop, local doctors or sometimes taken from government healthcare system which was decided by household head or sometimes husband and wife both.

\section{Recommendations}

Occurrence of diseases and overall status of health facilities was moderate according to the above results. However, there are some points where we can improve for better and good healthy nation. Such as:

- There is no community clinic in these areas so; government or related organization should set up it for smooth health service.

- For proper education, it is urgent to build primary and secondary school at the selected villages.

- Government organizations and NGOs should build awareness about health and nutritional knowledge among villagers.

- Government should smooth and more flexible in hospital services and doctors and stuff should more friendly and cooperative with village people and patients.

\section{REFERENCES}

[1] Begum S. H.Z. Rahman, M. Hossain, and B. Sen (1997). Health Dimension of Poverty in Rural Bangladesh: Some Evidence. In: Dynamics of Rural Poverty in Bangladesh, Bangladesh (1987-1994).

[2] Christman N (2005). The health seeking process. Cult. Med. Psychiat, 1(4):1357-68.

[3] MRahman Prince (2015). Health Status of Bangladesh.

[4] Rourke, J. (2008). Increasing the number of rural physicians. Canadian Medical Association Journal. 178: 322-325.

[5] Chakraborty N, Islam MA, Chowdhury RI, Bari W, Akhter HH (2003). Determinants of the use of maternal health services in rural Bangladesh. HP international, 18 (4):327-37.

[6] Mahadevi, Dharshini (2000). "Health for all in Gujarat, It is Achievable." Economic and Political Weekly, XXV (35 \& 36):3193-3204.

[7] Hossain, Shah Monir (2017). Non-Communicable Diseases (NCDs) in Bangladesh, An overview.

[8] WHO (2015) and ministry of planning and family welfare, Bangladesh.

[9] Henry J. Kaiser Family Foundation (2012).Hospital Beds (Per 10,000 Populations), 2005-2011.

[10] SyedMasud Ahmed; Md Awlad Hossain; Ahmed Mushtaque Raja Chowdhury \& Abbas Uddin Bhuiya (2011), the health workforce crisis in Bangladesh: shortage, inappropriate skill-mix and inequitable distribution, Human Resources for Health, 9 (3), doi: 10.1186/1478-4491-9-3.

[11] Oxford Dictionaries (2017). Sanitation, Definition of sanitation in English by Oxford Dictionaries".

[12] SuSanA (2008). Towards more sustainable sanitation solutions - SuSanA Vision Document. Sustainable Sanitation Alliance (SuSanA)

[13] Frisoli TM, Schmieder RE, Grodzicki T, MesserliFH (2012). Salt and hypertension: is salt dietary reduction worth the effort? Is J Med.125 (5):433-9. doi: 10.1016/j.amjmed.2011.10.023.

[14] WHO (2014).Non-communicable Diseases (NCD) Country Profiles, Bangladesh.

[15] Ruuskanen, O; Lahti, E; Jennings, LC; Murdoch, DR (2011). Viral pneumonia. Lancet.377 (9773): 1264-75.

[16] Rural Health Information Hub (RHIH). 2014. www.ruralhealthinfo.org. 